\title{
hl-con I, a factor VII-lgGFc chimeric protein targeting tissue factor for immunotherapy of uterine serous papillary carcinoma
}

\author{
E Cocco', Z Hu*,', CE Richter', S Bellone', F Casagrande', M Bellone', P Todeschini', G Krikun', D-A Silasi', \\ M Azodi', PE Schwartz', TJ Rutherford', N Buza², S Pecorelli ${ }^{3}$, CJ Lockwood' and AD Santin*,I \\ 'Department of Obstetrics, Gynecology and Reproductive Sciences, Yale University School of Medicine, Room 305 LSOG, 333 Cedar Street, PO Box \\ 208063, New Haven, CT 06520-8063, USA; ${ }^{2}$ Department of Pathology, Yale University School of Medicine, New Haven, CT, USA; ${ }^{3}$ Department of \\ Obstetrics and Gynecology, Division of Gynecologic Oncology, University of Brescia, Brescia, Italy
}

\begin{abstract}
BACKGROUND: Uterine serous papillary adenocarcinoma (USPC) is a highly aggressive variant of endometrial cancer. Human immunoconjugate molecule (hl-conl) is an antibody-like molecule targeted against tissue factor (TF), composed of two human Factor VII ( $\mathrm{V} \mathrm{VII}$ ) as the targeting domain, fused to human immunoglobulin (Ig) GI Fc as an effector domain. We evaluated hl-con I potential activity against primary chemotherapy-resistant USPC cell lines expressing different levels of TF.

METHODS: A total of 16 formalin-fixed, paraffin-embedded USPC samples were evaluated by immunohistochemistry (IHC) for TF expression. Six primary USPC cell lines, half of which overexpress the epidermal growth factor type II (HER2/neu) receptor at $3+$ levels, were assessed by flow cytometry and real-time PCR for TF expression. Sensitivity to hl-con I-dependent cell-mediated cytotoxicity (IDCC) was evaluated in 5-hour-chromium release assays. Finally, to investigate the effect of interleukin-2 (IL-2) on IDCC, $5-\mathrm{h}{ }^{51} \mathrm{Cr}$ assays were also conducted in the presence of low doses of IL-2 (i.e., $50-100 \mathrm{IU} \mathrm{ml}^{-1}$ ).

RESULTS: Cytoplasmic and/or membrane TF expression was observed in all 16 (100\%) USPC samples tested by IHC, but not in normal endometrium. High expression of TF was found in 50\% (three out of six) of the USPC cell lines tested by real-time PCR and flow cytometry when compared with normal endometrial cells (NECs; $P<0.00 I$ ). Uterine serous papillary adenocarcinoma cell lines overexpressing TF, regardless of their high or low HER2/neu expression, were highly sensitive to IDCC (mean killing \pm s.d., $65.6 \pm 3.7 \%$, range $57.5-77.0 \%, P<0.00 \mathrm{I}$ ), although negligible cytotoxicity against USPC was seen in the absence of hl-con I or in the presence of Rituximab control antibody. The addition of low doses of IL-2 further increased the cytotoxic effect induced by hl-con I against chemotherapy-resistant USPC.

CONCLUSION: hl-con I induces strong cytotoxicity against primary chemotherapy-resistant USPC cell lines overexpressing TF. The hl-con I may represent a novel therapeutic agent for the treatment of patients harbouring advanced, recurrent and/or metastatic USPC refractory to standard treatment modalities.

British Journal of Cancer (2010) I 03, 812-819. doi:10.1038/sj.bjc.6605760 www.bjcancer.com
\end{abstract}

Published online 10 August 2010

(c) 2010 Cancer Research UK

Keywords: uterine serous papillary cancer; hl-conl; immunotherapy; endometrial carcinoma

Endometrial cancer is the most common female genital tract malignancy in the United States, with an incidence of 40100 new cases and 7470 deaths in the United States in 2009 (Jemal et al, 2009). Two subtypes of endometrial carcinoma, namely type I and type II tumours, have been described on the basis of both clinical and histopathological variables (Bohkman, 1983). Type I endometrial cancers, which account for the majority of cases, are usually well differentiated and endometrioid in histology. These neoplasms are frequently diagnosed in younger women, are associated with a history of hyperestrogenism as the main risk factor, and typically have a favourable prognosis with appropriate therapy. In contrast, type II endometrial cancers include poorly

*Correspondence: Dr AD Santin or Dr Z Hu;

E-mail: alessandro.santin@yale.edu or zhiwei.hu@yale.edu

Revised I June 2010; accepted 7 June 2010; published online 10 August 2010 differentiated endometrioid tumours (G3-endometrial endometrioid carcinoma), serous papillary (uterine serous papillary adenocarcinoma (USPC)) and clear cells endometrial carcinomas (Bohkman, 1983). Although these tumours account for a minority of endometrial cancers the striking majority of relapses and deaths occur in this group of patients (Hendrickson et al, 1982; Goff et al, 1994; Chan et al, 2003; Schwartz, 2006). The development of novel therapeutic strategies against this aggressive subset of endometrial cancers remains a high priority.

Uterine serous tumours, which accounts for about $10 \%$ of endometrial cancers, have a higher propensity for lymphovascular invasion, and intraperitoneal as well as extra-abdominal spread, than endometrioid carcinoma. At the time of presentation, approximately $60-70 \%$ of women with USPC will have disease spread outside the uterus (Hendrickson et al, 1982). Unlike the histologically similar high-grade ovarian cancer, USPC is a chemoresistant disease from onset, with in vivo responses to combined 
cisplatin-based chemotherapy in the order of $20 \%$ and of short duration (Hendrickson et al, 1982; Levenback et al, 1992; Chan et al, 2003). Our group has recently reported HER2/neu overexpression by immunohistochemistry (IHC) and also amplification of the c-erbB2 gene by fluorescence in situ hybridisation in a large percentage of patients harbouring USPC (Santin et al, 2002, 2005a, b, c). These findings, recently confirmed by other groups (Diaz-Montes et al, 2006) including the Gynaecologic Oncology Group in a cooperative multicentric study (Grushko et al, 2008), have identified HER2/neu overexpression in USPC, as an independent variable associated with poor outcome and as the one that occurs more frequently in African-American women than in Caucasian women (Santin et al, 2002, 2005c).

Pathological angiogenesis, the formation of new capillary blood vessels from existing blood vessels into diseased tissues, has been previously reported to occur more frequently in endometrial carcinomas developing against a background of endometrial atrophy rather than carcinomas arising from a hyperplastic endometrium (Abulafia et al, 1999). Tissue factor, a transmembrane receptor for coagulation factor VII/VIIa, is aberrantly expressed in human cancers and on endothelial cells within the tumour vasculature (Contrino et al, 1996; Papetti and Herman, 2002). Importantly, tumour cells characterized by a high production of TF and vascular endothelial growth factor, a crucial initiator of angiogenesis, are known to generate solid tumours characterized by intense vascularity and highly aggressive behaviour (Abe et al, 1999). Consistent with this view, vascular endothelial growth factor expression at the invading tumour front is reported to be 4-10 times higher than in the inner tumour areas and is significantly associated with poor prognosis, particularly within stage I endometrial cancer (Abulafia et al, 1999; Bristow, 1999). Although a direct regulation of vascular endothelial growth factor expression in human tumour cells by the cytoplasmic tail of TF has been previously shown (Abe et al, 1999), recent studies indicate that type-2 proteinase activated receptor is intimately involved in TF-mediated signalling and angiogenesis (Ruf, 2007). These data suggest a potential direct role for TF in tumour growth (Ruf, 2007).

The hI-con 1 is a previously characterized immunoconjugate molecule developed against TF ( $\mathrm{Hu}$ et al, 1999; Hu and Garen, $2000,2001)$. It is composed of two identical protein chains consisting of human Factor VII (fVII) as the targeting domain fused to human immunoglobulin (Ig) G1 Fc as the effector domain; the two chains are held together by the disulphide bonds normally present in IgG. The hI-conl is designed to bind to TF with far higher affinity and specificity than that can be achieved with an anti-TF antibody. Indeed, the hI-con 1 has several important advantages over monoclonal antibodies for targeting TF, including: (1) the Kd for fVII binding to TF is about $10^{-12} \mathrm{M}$ (Waxman et al, 1992), in contrast to anti-TF antibodies that have a Kd in the range of $10^{-8}-10^{-9} \mathrm{M}$ for TF (Presta et al, 2001) and (2) the $\mathrm{hI}$-con 1 is produced by recombinant DNA technology, allowing a completely human hI-con1 to be made for future clinical trials. Because binding of the fVII to TF could induce disseminated intravascular coagulation, a potentially lethal vascular disease, an amino-acid substitution was introduced into the fVII domain of the hI-con1 (Lysine 341 to Alanine) to inhibit initiation of the coagulation pathway without reducing the strong affinity for TF (Hu et al, 1999; Dickinson et al, 2006). The human Fc domain of the hI-con1 may thus potentially activate powerful cytolytic responses mediated by antibodydependent cell-mediated cytotoxicity against both TF-expressing tumour cells and tumour vascular endothelial cells that bind the hI-con1 molecule. In this study, we evaluated for the first time the in vitro potential of hI-con 1 as a novel immunotherapeutic agent against biologically aggressive uterine serous tumours.

\section{METHODS}

\section{Tissue factor immunostaining of formalin-fixed USPC tissues}

Formalin-fixed, paraffin-embedded tissue blocks from 16 patients harbouring stage I (6 patients), stage II (2 patients), stage III (6 patients) and stage IV ( 2 patients) USPC were retrieved from the surgical pathology files at Yale University. Specimens were reviewed by a surgical pathologist (NB). The level of TF expression was then evaluated on the most representative block by standard immunohistochemical staining. For IHC, $4 \mu \mathrm{m}$ sections were cut from the formalin-fixed paraffin-embedded blocks. After deparaffinization and rehydration, endogenous peroxidase was blocked in $3 \% \mathrm{H}_{2} \mathrm{O}_{2}$. Steam and high $\mathrm{pH}(\mathrm{pH} 9)$ were used for antigen retrieval. The slides were then incubated overnight at $4{ }^{\circ} \mathrm{C}$ with monoclonal anti-TF antibody (no. 4509, 1:10 dilution; American Diagnostica, Stamford, CT, USA). EnVisionTM system (Dako, Carpinteria, CA, USA) was used for secondary detection and the reactions were visualised with diaminobenzidine. Appropriate positive and negative controls were used with each case. Both cytoplasmic and membranous immunoreactivity were considered positive. Immunostaining was assessed using a semi-quantitative scoring system, as follows: 0 , negative $(0-5 \%$ staining); $1+$, weakly positive $(10-20 \%) ; 2+$, moderately positive $(20-50 \%)$; $3+$ and $4+$, strongly positive $(50-75 \%$ and $>75 \%$, respectively), as previously described (Kaushal et al, 2008).

\section{Establishment of USPC cell lines}

Primary USPC tumour cell lines from six patients with invasive USPC were obtained from fresh tumour biopsies collected at the time of surgery, under the approval of the Institutional Review Board. Tumours were staged according to the International Federation of Gynaecologists and Obstetricians operative staging system. Six primary USPC cell lines (USPC-ARK-1, USPC-ARK-2, USPC-ARK-3, USPC-ARK-4, USPC-ARK-5 and USPC-ARK-6) were established after sterile processing of the tumour samples from surgical biopsies as described previously (Cross et al, 2010). Source-patient characteristics of these six USPC cell lines are described in Table 1. The amplification of the c-erbB2 gene by fluorescence in situ hybridisation, expression levels of HER2/neu receptor by IHC and mRNA expression levels by quantitative realtime PCR ( $\mathrm{qRT}$ - PCR) for these primary USPC cell lines have been recently reported (El-Sahwi et al, 2010).

\section{Quantitative real-time PCR}

RNA isolation from all the six primary USPC cell lines used in the cytotoxicity experiments were performed using TRIzol Reagent (Invitrogen, Carlsbad, CA, USA) according to the manufacturer's instructions. Quantitative PCR was performed using a 7500 Real-time

Table I Patient characteristics, from which the six USPC cell lines were established

\begin{tabular}{lccccc}
\hline Patient & $\begin{array}{c}\text { Age } \\
\text { (years) }\end{array}$ & Race & $\begin{array}{c}\text { Year of } \\
\text { diagnosis }\end{array}$ & $\begin{array}{c}\text { FIGO } \\
\text { stage }\end{array}$ & $\begin{array}{c}\text { USPC } \\
\text { histopathology }\end{array}$ \\
\hline USPC-ARK-I & 62 & AA & 1997 & IVA & Pure \\
USPC-ARK-2 & 63 & AA & 1998 & IVB & Pure \\
USPC-ARK-3 & 59 & AA & 2006 & IVB & Mixed \\
USPC-ARK-4 & 73 & C & 2004 & IVB & Pure \\
USPC-ARK-5 & 73 & AA & 2006 & IIIC & Pure \\
USPC-ARK-6 & 62 & C & 2005 & IB & Mixed \\
\hline
\end{tabular}

Abbreviations: $A A=$ African American; $C=$ Caucasian; $F \mid G O=$ International Federation of Gynaecologist and Obstetrics; USPC =uterine serous papillary adenocarcinoma. 
PCR System with the manufacturer's recommended protocol (Applied Biosystems, Foster City, CA, USA) to evaluate expression of TF in all samples. Each reaction was run in duplicate. Briefly, $5 \mu \mathrm{g}$ of total RNA from each sample was reverse transcribed using SuperScript III first-strand cDNA synthesis (Invitrogen). A total of $5 \mu \mathrm{l}$ of reverse transcribed RNA samples (from $500 \mu \mathrm{l}$ of total volume) was amplified using the TaqMan Universal PCR Master Mix (Applied Biosystems) to produce PCR products specific for TF. The primers and probe for TF were obtained from Applied Biosystems (assay ID Hs01076032_m1). The comparative threshold cycle $\left(C_{T}\right)$ method (Applied Biosystems) was used to determine gene expression in each sample relative to the value observed in the lowest non-malignant endometrial epithelial-cell sample, using glyceraldehyde-3-phosphate dehydrogenase (assay ID Hs99999905_m1) RNA as internal control.

\section{Flow cytometry}

Clinical grade hI-con1 was produced for Iconic Therapeutics Inc. (Atlanta, GA, USA) by Laureate Pharma, (Princeton, NJ, USA) by cultivation of baby hamster kidney cells transfected with a vector containing the gene sequence originally described by $\mathrm{Hu}$ and Garen (2000, 2001; Hu et al, 1999). The protein was purified by a series of chromatographic steps to a purity adequate for clinical use, formulated in $15 \mathrm{~mm}$ HEPES, $150 \mathrm{mM} \mathrm{NaCl}, 5 \mathrm{mM} \mathrm{CaCl}_{2}, 25 \mathrm{~mm}$ arginine and $0.01 \%$ Tween $80, \mathrm{pH} 7.4$ buffer, and was sterile filtered. It was provided in aliquots of $80 \mu \mathrm{l}$ at a stock concentration of $350 \mu \mathrm{g} \mathrm{ml}^{-1}$, which were used for our flow cytometry and hI-con1dependent cell-mediated cytotoxicity (IDCC) studies. Briefly, USPC cell lines and phytohemagglutinin (PHA)-stimulated control peripheral blood lymphocytes (PBLs) were stained with hI-con1 at a concentration of $30 \mu \mathrm{g} \mathrm{ml}^{-1}$ for $30 \mathrm{~min}$ on ice or with a commercially available fluorescein isothiocyanate-conjugated mouse anti-human TF Ig (i.e., positive control; BioSource International, Camarillo, CA, USA). After hI-con1 staining, cells were washed twice with the same buffer and secondary goat-anti-mouse antibody (IgG1FITC (fluorescein isothiocyanate), catalogue no. F0767 Sigma Aldrich, St Louis, MO, USA) was added for further $30 \mathrm{~min}$. Analysis was conducted with a FACSCalibur instrument using Cell Quest software (Becton Dickinson, Franklin Lakes, NJ, USA).

\section{Tests for IDCC}

A standard 5 -h chromium $\left({ }^{51} \mathrm{Cr}\right)$ release assay was performed to measure the cytotoxic reactivity of Ficoll-Hypaque-separated PBLs from several healthy donors in combination with hI-con1 against USPC target cell lines. The release of ${ }^{51} \mathrm{Cr}$ from the target cells was measured, as described (Santin et al, 1999), as evidence of tumour cell lysis after exposure of tumour cells to various concentrations of hI-con1 (ranging from 1 to $80 \mu \mathrm{g} \mathrm{ml}^{-1}$ ) and different target/effector cell ratios. Controls included the incubation of target cells alone or with PBLs, or monoclonal antibody $(\mathrm{mAb})$ separately. The chimeric anti-CD20 mAb Rituximab (Rituxan; Genentech, San Francisco, CA, USA) was used as control in all bioassays. The hI-con1-dependent cell-mediated cytotoxicity was calculated as the percentage of killing of target cells observed with $\mathrm{mAb}$ plus effector cells as compared with ${ }^{51} \mathrm{Cr}$ release from target cells incubated alone.

\section{Interleukin-2 enhancement of IDCC}

To investigate the effect of IL-2 on IDCC, effector PBLs were incubated for $5 \mathrm{~h}$ at $37^{\circ} \mathrm{C}$, with a final concentration of IL-2 (Aldesleukin; Chiron Therapeutics, Emeryville, CA, USA) ranging from 50 to $100 \mathrm{IU} \mathrm{ml}^{-1}$ in 96 -well microtiter plates. Target cells were primary USPC cell lines exposed to hI-con1 (concentrations ranging from 1 to $80 \mu \mathrm{g} \mathrm{ml}^{-1}$ ), whereas controls included the incubation of target cells alone or with PBLs in the presence or absence of IL-2 or mAb, respectively. Rituximab was used as a control mAb. The hI-con1-dependent cell-mediated cytotoxicity was calculated as the percentage of killing of target cells observed with mAb plus effector PBLs, as compared with target cells incubated alone. Each experiment was performed with PBLs collected from multiple normal donors and results from a representative donor are presented.

\section{Statistical analysis}

For qRT-PCR data, the right-skewing was removed by taking copy-number ratios relative to the lowest expressing normal endometrial cell (NEC) sample ('relative copy numbers'), $\log _{2}$ transforming them to $\triangle \mathrm{CT}$ s, and comparing the results via unequal variance $t$-test for the USPC $v s$ NEC difference. Group means with 95\% confidence limits (confidence intervals) were calculated by computing them on the $\Delta \mathrm{CTs}$ and then reverse transforming the results to obtain means (95\% confidence intervals) of relative copy numbers. Differences in TF expression by flow cytometry were analysed by the unpaired $t$-test. Kruskal-Wallis test and $\chi^{2}$-analysis was used to evaluate differences in hI-con1-induced cellular cytotoxicity levels in primary tumour cell lines. Statistical analysis was performed using SPSS version 15 (SPSS, Chicago, IL, USA). A $P$-value of $<0.05$ was considered statistically significant.

\section{RESULTS}

\section{Tissue-factor expression by IHC in USPC samples}

We performed immunohistochemical analysis of TF protein expression on formalin-fixed tumour tissues from 16 paraffinembedded uterine serous carcinoma specimens. As representatively shown in Figure 1, with no exception, all USPC samples that were tested showed either membrane and/or cytoplasmic immunoreactivity for TF (i.e., all 16 samples $=100 \%$ ), whereas the non-neoplastic endometrial controls were negative. The staining intensity was focal $(1+)$ in nine cases, moderately positive $(2+)$ in four cases and strongly positive $(3+)$ in two cases.

\section{Tissue-factor expression by $\mathrm{qRT}$ - PCR in USPC primary cell lines}

A total of six primary USPC lines, half of which overexpress HER2/neu at $3+$ level and show amplification of the $C$-erbB2 gene by fluorescence in situ hybridisation, were tested for TF expression by qRT - PCR. Table 2 shows mRNA levels for TF in all USPC cell lines relative to the value observed in the lowest non-malignant endometrial epithelial-cell sample. Of the six tumours tested, three showed a high mRNA copy number (i.e., USPC-ARK-2, USPCARK-3 and USPC-ARK-6) ranging from 280 to 816 (Table 2). The TF expression between these USPC cell lines and NECs was statistically significant at $P=0.01$. The fold change in the mean relative copy numbers between high USPC TF expressers $v s$ NECs was $8.7(P=0.01)$. In contrast, low TF expression using $\mathrm{qRT}-\mathrm{PCR}$ was detected in the remaining three USPC cell lines (USPC-ARK-1, USPC-ARK-4 and USPC-ARK-5; range of copies from 4 to 17 ; Table 2). The mean copy number in USPC samples overexpressing TF was 476.3 vs 12.3 in the low USPC TF expressers $(P<0.01)$. High level of TF was detected in two out of three USPC cell lines harbouring the amplification of the c-erbB2 gene and in one out of three USPC cell lines showing low HER2/neu expression (Table 2).

\section{Tissue-factor expression by flow cytometry in primary USPC cell lines}

Surface TF receptor expression was evaluated by fluorescenceactivated cell sorting analysis in all six primary USPC cell lines using hI-con 1 and an anti-human TF control mAb. As negative controls, several PHA-stimulated PBLs established from healthy 

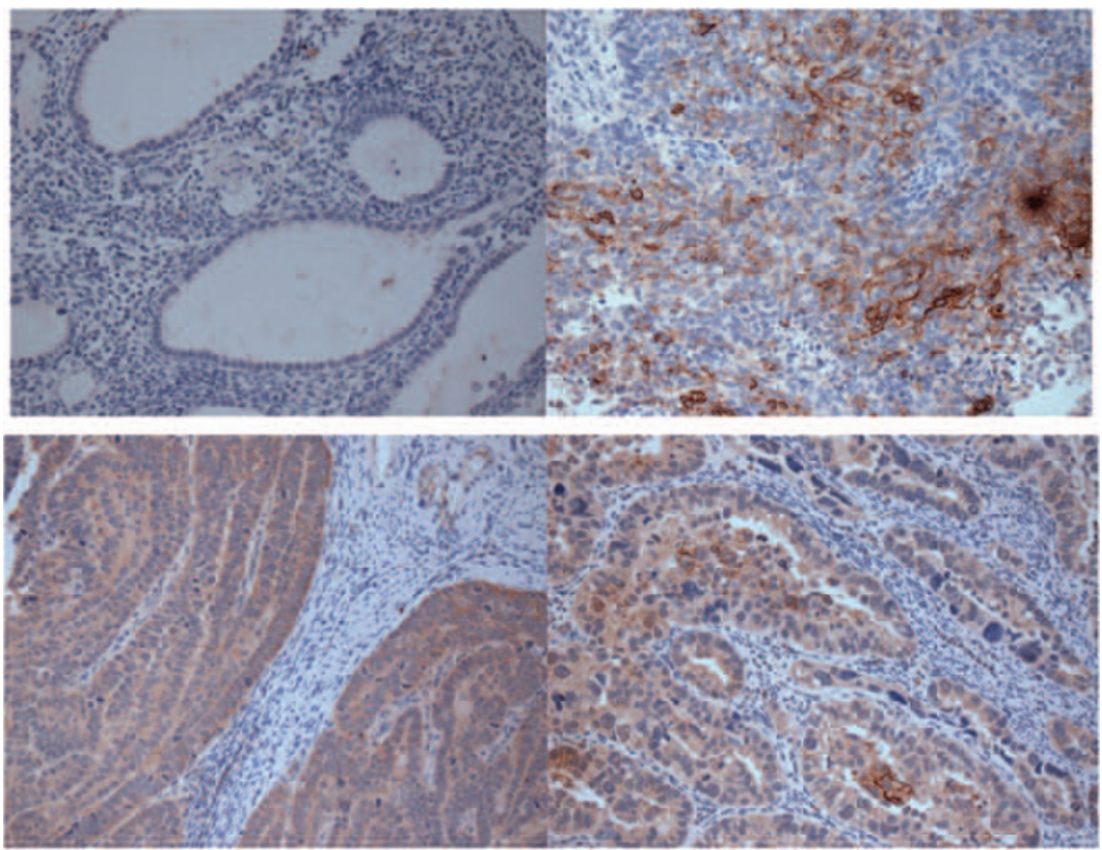

Figure I Representative immunohistochemistry localisation analyses of tissue factor (TF) in uterine serous papillary adenocarcinoma (USPC) specimens. Upper left panel: normal endometrium, which is negative for TF. Lower left panel: USPC specimen showing cytoplasmic expression of TF. Upper right panel: USPC specimen showing membrane expression of TF. Lower right panel: USPC specimen showing both cytoplasmic and membrane expressions of TF. Original magnification: $\times 200$.

Table 2 Tissue factor and HER2/neu expression in primary USPC cell lines

\begin{tabular}{|c|c|c|c|c|c|}
\hline Sample & $\begin{array}{l}\text { HER2/neu IHC } \\
\text { Cell block }\end{array}$ & $\begin{array}{l}\text { HER2/neu FISH } \\
\text { Cell block }\end{array}$ & $\begin{array}{l}\text { Tissue factor } R T-P C R \\
\text { mRNA copy number }\end{array}$ & \multicolumn{2}{|c|}{ Tissue factor flow cytometry } \\
\hline Control & - & - & 1 & - & - \\
\hline USPC-ARK-2 & $3+$ & 5.2 & 332.3 & 100.0 & 92.2 \\
\hline USPC-ARK-3 & $3+$ & 4.7 & 280.2 & 100.0 & 89.8 \\
\hline USPC-ARK-4 & 0 & 1.6 & 4.7 & 75.6 & 25.8 \\
\hline
\end{tabular}

Abbreviations: FISH = fluorescence in-situ hybridization; $I H C=$ immunohistochemistry; $\mathrm{MFI}=$ mean fluorescence intensity; $\mathrm{RT}-\mathrm{PCR}=$ real-time $\mathrm{PCR} ; \mathrm{USPC}=$ uterine serous papillary adenocarcinoma.

donors or the same USPC patients, from whom the tumour cell lines had been established, were also studied. In agreement with the RT-PCR results, high reactivity against TF was found using flow cytometry in USPC-ARK-2, USPC-ARK-3 and USPC-ARK-6 cell lines stained with hI-con1 (Table 2, Figure 2). In contrast, significantly lower TF surface expression was detected in USPCARK-1, USPC-ARK-4 and USPC-ARK-5 cell lines (Table 2, Figure 2). Mean fluorescence intensity ranged from 89 to 92 in high USPC TF expressers $v s$ a mean fluorescence intensity ranged from 25 to 53 in low USPC TF expressers $(P<0.02)$. Low TF expression was also observed in the multiple PHA-stimulated PBL lines used as further controls (i.e., mean fluorescence intensity from 40 to 45; high USPC TF expressors $v s$ PHA-stimulated PBLs: $P<0.01)$.

\section{Uterine serous papillary adenocarcinoma overexpressing TF are highly resistant to natural killer (NK) cell activity but sensitive to IDCC}

All the six primary USPC cell lines available were tested for their sensitivity to NK cell cytotoxicity when challenged with heterologous PBLs, collected from several healthy donors, in a standard $5-\mathrm{h}{ }^{51} \mathrm{Cr}$ release assay. Uterine serous papillary adenocarcinoma primary cell lines were consistently found to be resistant to NK cell-mediated cytotoxicity when combined with PBLs at E:T ratios varying at 25:1-50:1 (range of cytotoxicity from $0.2-9 \%$ with all $\mathrm{E}: \mathrm{T}$ ratios). Similarly, USPC cell lines incubated with rituximab $\left(2.5 \mu \mathrm{g} \mathrm{ml}^{-1}\right)$ control antibody showed no significant cytotoxicity (range from $0.1-8 \%$ ). We then investigated the sensitivity of USPC cell lines expressing different levels of $\mathrm{TF}$ to heterologous PBLs in the presence of hI-con1 $\left(30 \mu \mathrm{g} \mathrm{ml}^{-1}\right)$. While negligible levels of cytotoxicity were detected against PHA-stimulated PBLs (i.e., TF-negative controls, data not shown), tumour cell lines expressing high levels of TF (i.e., USPCARK-2, USPC-ARK-3 and USPC-ARK-6), regardless of their high or low HER2/neu expression, were found to be highly sensitive to hI-con1-induced antibody-dependant cell death (mean \pm s.d., $65.6 \pm 3.7 \%$; range, 57.5-77.0\%; Figure 3; $P<0.001$ ). In contrast, tumour cell lines expressing low levels of TF (i.e., USPC-ARK-1, USPC-ARK-4 and USPC-ARK-5) were killed at significantly lower levels when compared with the high TF-expresser USPC cell lines 


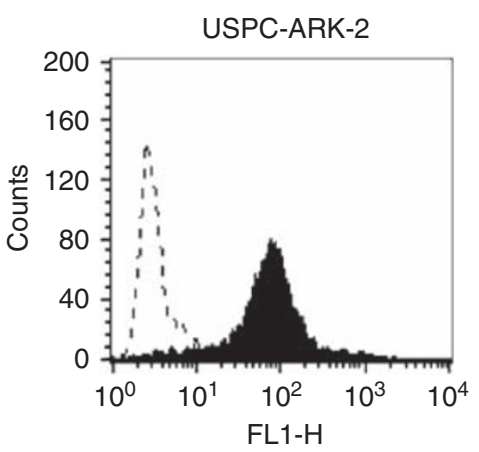

USPC-ARK-1

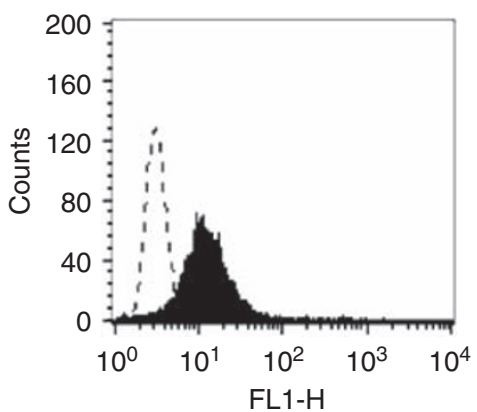

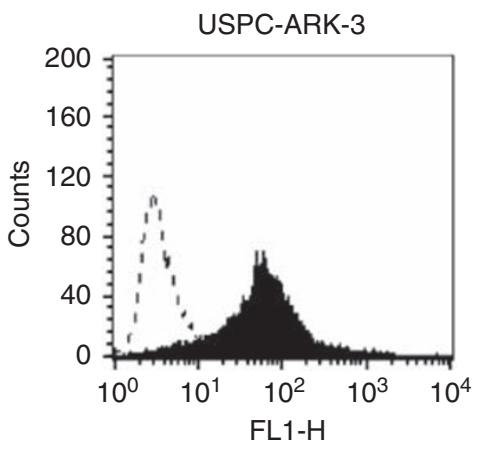

USPC-ARK-4

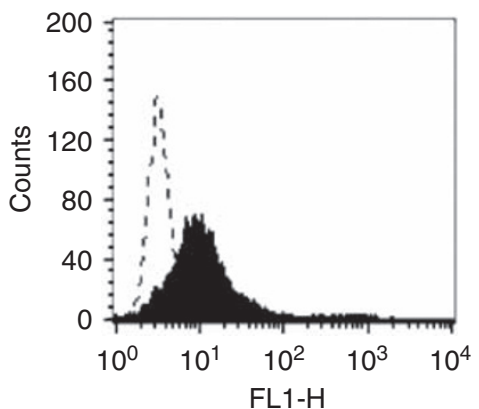

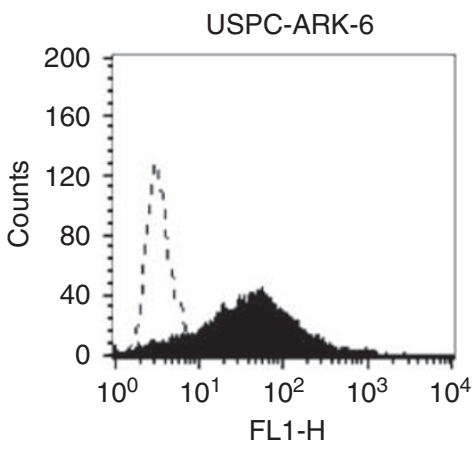

USPC-ARK-5

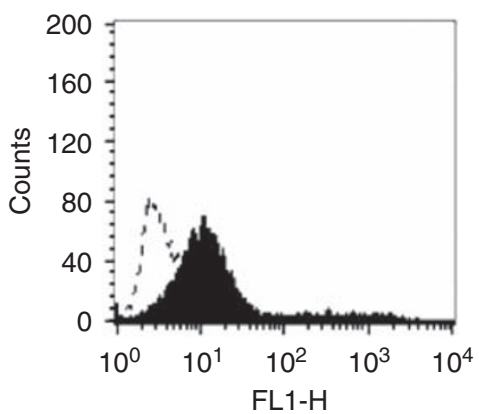

Figure 2 Flow cytometry histograms of primary uterine serous papillary adenocarcinoma (USPC) cell lines showing high (USPC-ARK-2, USPC-ARK-3 and USPC-ARK-6) and low (USPC-ARK-I, USPC-ARK-4 and USPC-ARK-5) expression of tissue factor. Dashed line represents isotype and solid black represents human immuno-conjugate molecule.
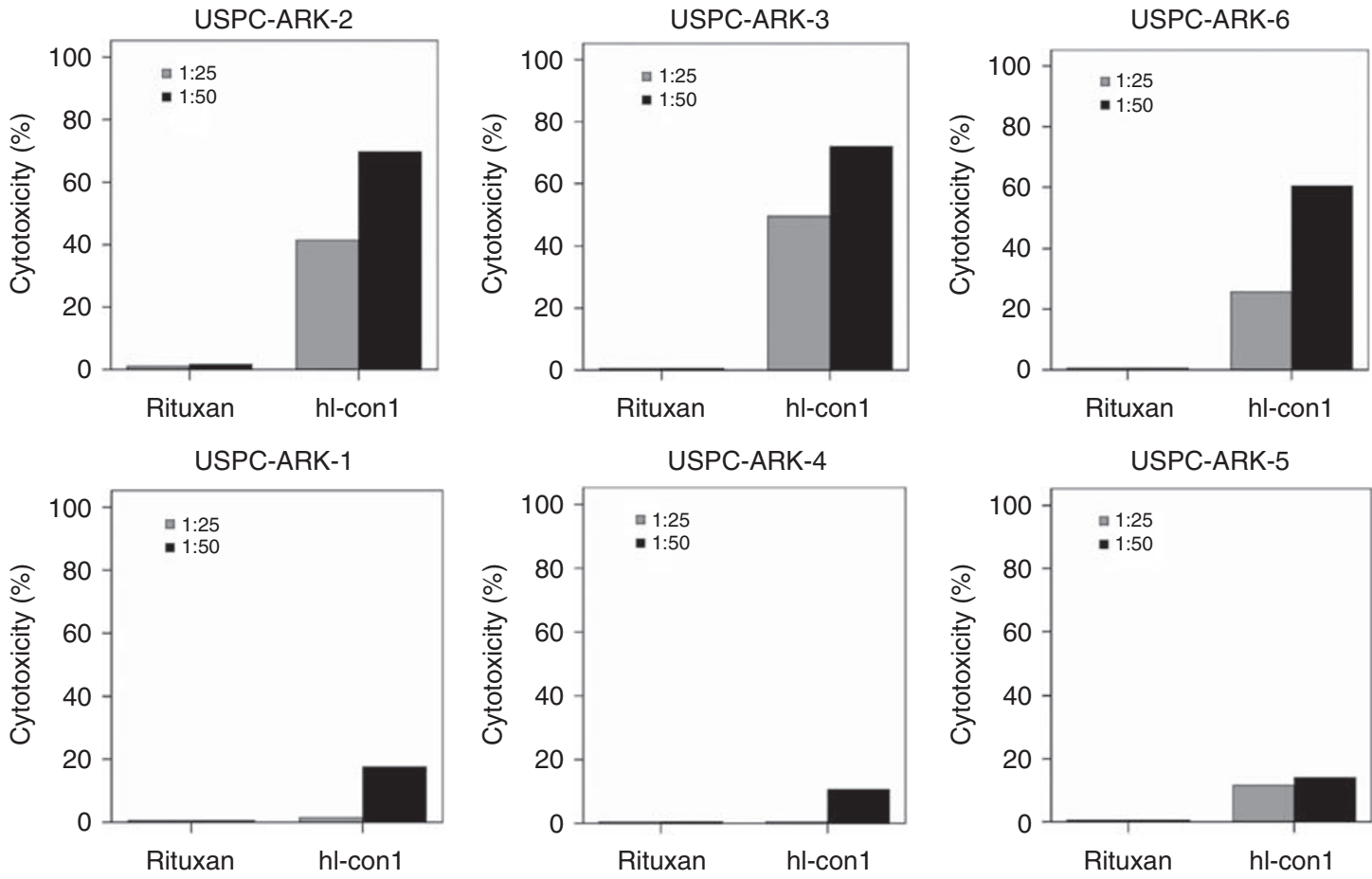

Figure 3 Representative cytotoxicity experiments using human immuno-conjugate molecule (hl-conl) against primary uterine serous papillary adenocarcinoma (USPC) with high vs low tissue factor (TF) expression. Upper panels: high TF USPC cell lines. Lower panels: low TF USPC cell lines. Negligible cytotoxicity was detected in the absence of hl-conl or in the presence of rituximab control monoclonal antibody.

(Figure 3; $P<0.001)$. Nevertheless, in the latter experiments, low TF-expresser USPC cell lines incubated with hI-con1 were killed at significantly higher level when compared with the same tumours incubated with rituximab control mAb (mean hI-con1 killing low expresser USPC \pm s.d. $=14.0 \pm 2.0 \%$; range, $10.6-17.6 \%$; Figure $3 ; P<0.02)$, or when compared with PHA-stimulated PBL control incubated with hI-con 1 (mean killing PBLs $=3.0 \%$; range, $0.6-6 \%)$. 


\section{Interleukin-2 enhancement of IDCC against USPC}

To investigate the effect of low doses of IL-2 in combination with hI-con1 $\left(30 \mu \mathrm{g} \mathrm{ml}^{-1}\right)$ on IDCC against USPC cell lines, PBLs from healthy donors were incubated for $5 \mathrm{~h}$ in the presence of $50-100 \mathrm{IU} \mathrm{ml}^{-1}$ of IL-2. As shown in Figure 4, for all primary USPC showing TF overexpression, (i.e., USPC-ARK-2, USPC-ARK-3 and USPC-ARK-6) IDCC was increased in the presence of low doses of IL-2. Administration of $50-100 \mathrm{IU} \mathrm{ml}^{-1}$ of IL-2 to the effector PBLs at the start of the assay increased the cytotoxic activity against USPC cell lines overexpressing TF compared with the use of hI-con 1 alone, (Figure $4 ; P<0.01$ ) whereas no significant increase in cytotoxicity was detected after 5-h IL-2 treatment in the absence of hI-con 1 or in the presence of Rituximab control mAb (Figure 4). These results suggest that low levels of IL-2 may enhance hI-con1-mediated cell-cytotoxicity in USPC cell lines in vitro.

\section{DISCUSSION}

Tissue factor is involved in pathological angiogenesis and is abnormally overexpressed in multiple human tumours and in tumour vascular endothelial cells but not in normal quiescent vascular endothelial cells (Contrino et al, 1996; Papetti and Herman, 2002). Although TF, as a cell-surface receptor, is physiologically expressed on extravascular cells of many organs and in the adventitial layer of the blood vessel wall, it is sequestered by coagulation factor VII (fVII), a natural ligand for $\mathrm{TF}$, at these sites by the tight endothelial-cell layer of the normal vasculature (Contrino et al, 1996; Papetti and Herman, 2002). Thus, pathologically expressed TF may provide a target for the development of novel cancer therapies that are effective not only against tumour cells but also against tumour blood vessels (Hu et al, 1999; Hu and Garen, 2000, 2001; Alessi et al, 2004).

In this study, we have evaluated TF expression using IHC in multiple formalin-fixed, paraffin-embedded USPC samples. In addition, we have studied TF expression at RNA and protein level in six primary USPC cell lines and subsequently tested the in vitro activity of hI-con1, a previously characterized immunoconjugate molecule developed against TF ( $\mathrm{Hu}$ et al, 1999; Hu and Garen, 2000,2001 ), as a novel therapy against these chemotherapyresistant USPC cell lines in vitro (Cross et al, 2010). We observed TF overexpression on the membrane and/or in the cytoplasm of all the USPC samples tested using IHC (all 16=100\%) whereas normal control endometrial cells were found consistently negative for TF expression. This suggests that TF expression may be a common and an important event in malignant transformation of the endometrium, particularly for biologically aggressive type II endometrial cancer. Consistent with this view, TF was also found to be highly expressed in three out of six primary USPC cell lines available for this study, using qRT-PCR and flow cytometry. The TF expression has been previously reported in endometrial endometrioid adenocarcinoma cell lines (i.e., the most common and less aggressive variant of human endometrial cancer; Kato et al, 2005, 2008). However, to our knowledge, the overexpression of TF in primary chemotherapy-resistant uterine serous tumours has not been previously studied. Of interest, in the primary USPC tested, both HER2/neu-positive and HER2/neu-negative cell lines were found to overexpress the TF. These data thus suggest that USPC, regardless of their different sensitivity/resistance to various chemotherapy agents (Cross et al, 2010) or anti-HER2/neutargeted therapies, (i.e., trastuzumab and pertuzumab; El-Sahwi et al, 2010) may potentially respond to hI-con 1 therapy.

Several studies have shown that tumour cell TF has an important role in tumour metastatic process, possibly by induction of the coating of the tumour cell with fibrin that would trap the cells in the microvasculature, thereby aiding metastases (Mueller et al, 1992). More recently, however, a possible direct role for TF
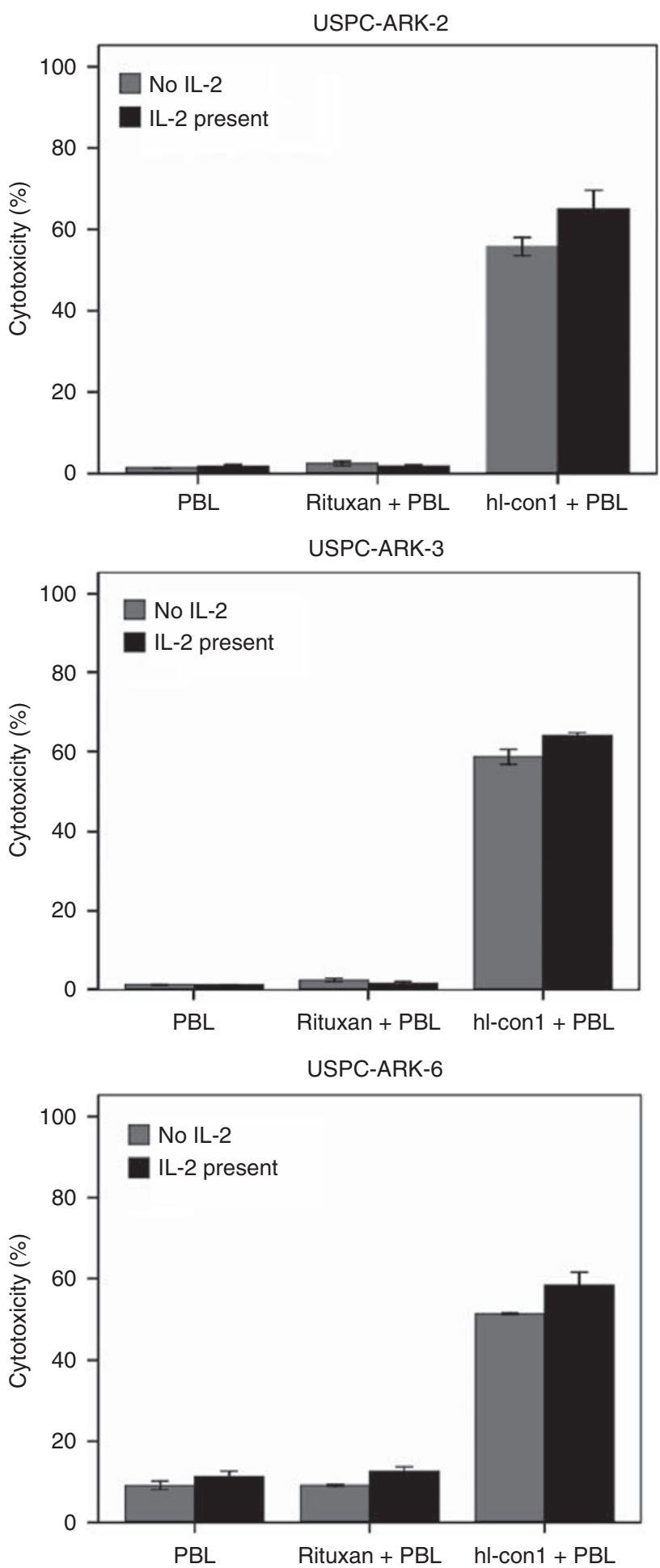

Figure 4 Effect of low doses of interleukin-2 (IL-2) in combination with human immuno-conjugate molecule (hl-conl; $30 \mu \mathrm{g} \mathrm{m}^{-1}$ ) on antibodydependent cell-mediated cytotoxicity against USPC-ARK-2, USPC-ARK-3 and USPC-ARK-6 primary cell lines (effectors to target ratio 25:I). Peripheral blood lymphocytes (PBLs) from healthy donors were incubated for $4 \mathrm{~h}$ in the presence of $100 \mathrm{IU} \mathrm{ml} \mathrm{ml}^{-1}$ of IL-2. The hl-conl-mediated antibody-dependent cell-mediated cytotoxicity was significantly increased in the presence of low doses of IL-2. No significant increase in cytotoxicity was detected after 4-h IL-2 treatment in the absence of hl-conl or in the presence of the rituximab isotype control monoclonal antibody. 
in tumour growth has also been suggested by studies showing a dramatically reduced tumour growth in mice, where a selective reduction in TF was achieved using small interfering RNA (Yu et al, 2005). Of great interest, in these studies, is that the reduction in TF expression did not affect growth of the tumour cells in vitro, suggesting that TF-mediated enhancement of tumour growth requires a factor present in vivo that is not present when cells are grown in vitro ( $\mathrm{Yu}$ et al, 2005). A potential candidate to explain these findings is therefore FVIIa, which would form a TF:FVIIa complex on the surface of tumour cells in vivo leading to the activation of type- 2 proteinase activated receptor-dependent signalling (Ruf, 2007). These findings combined with our results suggest that TF overexpression may potentially provide an additional growth advantage to biologically aggressive USPC in vivo.

The potential cytotoxic activity of hI-con 1 against human melanoma and prostate tumour cells has previously been shown by $\mathrm{Hu}$ et al (Hu et al, 1999; $\mathrm{Hu}$ and Garen, 2000, 2001). In our study, we extended the results of $\mathrm{Hu}$ et al ( $\mathrm{Hu}$ et al, 1999) evaluating the cytotoxic potential of hI-con1 against multiple biologically aggressive, high-grade serous endometrial cancer cell lines. We found all tested primary tumours showing high TF expression, regardless of their high or low HER2/neu expression, to be highly susceptible to IDCC in the presence of effector cells. In this regard, it is worth noting that although these cell lines were resistant to NK-cell cytotoxic activity, IDCC resulted in killing of up to $65 \%$ of tumour cells in $5-\mathrm{h}{ }^{51} \mathrm{Cr}$ release assays. Taken together, these in vitro results strongly suggest that TF may provide a novel target for USPC and its tumour vasculature, which should likely result in hI-con1-induced lysis of tumour cells as well as endothelial cells in vivo.

hI-con1-mediated tumour cell lysis depends on the presence of effector cells (Hu et al, 1999; Hu and Garen, 2000, 2001), and CD56-positive lymphocytes have been shown to contribute most to the effect of IgG1-mediated antibody-dependent cell-mediated cytotoxicity in vitro as well as in vivo (Ortaldo et al, 1987; Clynes et al, 2000). Interleukin-2 treatment leads to the activation of NK cell cytotoxicity and to the expansion of the NK cell population within the PBL in vivo (Fehniger et al, 2000). Consistent with its immunostimulatory effect on NK cells, IL-2 has been previously shown to work synergistically with monoclonal antibodies in vivo (Caron et al, 1995). Importantly, contrary to the significant toxicity of high-dose recombinant IL-2 therapy, low-dose IL-2 administered subcutaneously or by continuous infusion has been shown to have high clinical and immunological activity with a low-toxicity profile (Fehniger et al, 2000). These findings are particularly interesting because a modulation of the number and function of NK cells has been associated with tumour progression in both experimental and animal models, and pre-treatment of the PBLs with IL-2 can increase the cytotoxicity levels in patients with suppressed antibody-dependent cell-mediated cytotoxicity to levels similar to that in normal donors (Ortaldo et al, 1987). Consistent with this data, our in vitro experiments reveal a significant increase in hI-con1-induced cytotoxicity after the brief incubation of PBLs and tumour cells with IL-2 compared with the cytotoxicity induced by hI-con 1 in the absence of IL-2. Interleukin-2 seems to, therefore, enhance the cytotoxic potential of the effector cells. The administration of low doses of IL-2 might therefore be a valid therapeutic option to increase IDCC in heavily pretreated endometrial cancer patients.

Although the in vivo use of hI-con 1 in animals harbouring xenografts of human USPC has not been studied in our current report, previous studies have shown the safety and efficacy of using hI-con 1 in vivo in mice carrying mouse and human tumours (Hu et al, 1999; Hu and Garen, 2000, 2001), harbouring human implants of pathological endometriosis (Krikun et al, 2010), as well as in eradicating choroidal neovascularization in mouse and pig models of wet-form macular degeneration (Tezel et al, 2007). Thus, current studies in multiple animal models suggest that hI-con1 use is potentially safe in vivo and, therefore, may have great potential as a neovascular targeting agent, with broad applications for the immunotherapy of pathological angiogenesis-involved diseases in humans.

In conclusion, expression of $\mathrm{TF}$ in chemotherapy-resistant USPC makes hI-con 1 an attractive agent for immunotherapy of chemotherapy-resistant endometrial cancer. This holds particularly true for USPC patients, in whom other potentially effective targeted in vivo therapies (i.e., trastuzumab; Jewell et al, 2006; Villella et al, 2006; Santin et al, 2008) are not indicated owing to the lack of expression of its target HER2/neu on USPC cells. In this study, we have shown significant hI-con1-mediated killing of high-grade, chemotherapy-resistant USPC, for which treatment options are very limited. Human immuno-conjugate molecule (hI-con1) might therefore represent a fascinating new addition to the treatment of this aggressive disease and, potentially, multiple other human tumours overexpressing TF. Clinical trials will ultimately determine the validity of this novel therapeutic approach.

\section{ACKNOWLEDGEMENTS}

We thank Dr William Konigsberg and Dr Alan Garen for initiating the collaboration with $\mathrm{ZH}, \mathrm{GK}$ and $\mathrm{CJL}$ on mouse icon immunotherapy of human endometrial cancer, and Iconic Therapeutics Inc. for providing hI-con1 protein free of charge for our studies. This work is supported in part by Grants from the Angelo Nocivelli, the Berlucchi and the Camillo Golgi Foundation, Brescia, Italy; NIH R01 CA122728-01A2 to ADS; and Grants $501 / A 3 / 3$ and 0027557 from the Italian Institute of Health (ISS) to ADS; and the Komen Award (BCTR0601204) from Susan G Komen for the Cure Foundation and the Biomedical Research Grant (2009-0096) from Connecticut Department of Public Health to $\mathrm{ZH}$. This investigation was also supported by NIH Research Grant CA-16359 from the National Cancer Institute.

\section{REFERENCES}

Abe K, Shoji M, Chen J, Bierhaus A, Danave I, Micko C, Casper K, Dillehay DL, Nawroth PP, Rickles FR (1999) Regulation of vascular endothelial growth factor production and angiogenesis by the cytoplasmic tail of tissue factor. Proc Natl Acad Sci USA 96: 8663-8668

Abulafia O, Triest WE, Sherer DM (1999) Angiogenesis in malignancies of the female genital tract. Gynecol Oncol 72: 220-231

Alessi P, Ebbinghaus C, Neri D (2004) Molecular targeting of angiogenesis. Biochim Biophys Acta 4(1654): 39-49

Bohkman JV (1983) Two pathogenetic types of endometrial carcinoma. Gynecol Oncol 15: $10-17$

Bristow RE (1999) Endometrial cancer. Curr Opin Oncol 11: 388-393
Caron PC, Lai LT, Scheinberg DA (1995) Interleukin-2 enhancement of cytotoxicity by humanized monoclonal antibody M195 (anti-CD33) in myelogenous leukemia. Clin Cancer Res 1: 63-70

Chan JK, Loizzi V, Youssef M, Osann K, Rutgers J, Vasilev SA, Berman ML (2003) Significance of comprehensive surgical staging in noninvasive papillary serous carcinoma of the endometrium. Gynecol Oncol 90: 181-185 Clynes RA, Towers TL, Presta LG, Ravetch JV (2000) Inhibitory Fc receptors modulate in vivo cytotoxicity against tumor targets. Nat Med 6: $443-446$

Contrino J, Hair G, Kreutzer DL, Rickles FR (1996) In situ detection of tissue factor in vascular endothelial cells: correlation with the malignant phenotype of human breast disease. Nat Med 2: 209-215 
Cross SN, Cocco E, Bellone S, Anagnostou VK, Brower SL, Richter CE, Siegel ER, Schwartz PE, Rutherford TJ, Santin AD (2010) Differential sensitivity to platinum-based chemotherapy in primary uterine serous papillary carcinoma cell lines with high versus low HER-2/neu expression in vitro. Am J Obstet Gynecol (in press)

Diaz-Montes TP, Ji H, Sehdev AE, Zahurak ML, Kurman RJ, Armstrong DK, Bristow RE (2006) Clinical significance of Her-2/neu overexpression in uterine serous carcinoma. Gynecol Oncol 100: 139-144

Dickinson CD, Kelly CR, Ruf W (2006) Identification of surface residues mediating tissue factor binding and catalytic function of the serine protease factor VIIa. Proc Natl Acad Sci USA 93: 14379-14384

El-Sahwi K, Bellone S, Cocco E, Cargnelutti M, Casagrande F, Bellone M, Abu-Khalaf M, Buza N, Tavassoli FA, Hui P, Silasi DA, Azodi M, Schwartz PE, Rutherford TJ, Pecorelli S, Santin AD (2010) In vitro activity of pertuzumab in combination with trastuzumab in uterine serous papillary adenocarcinoma. Br J Cancer 102: 134-143

Fehniger TA, Bluman EM, Porter MM, Mrozek E, Cooper MA, VanDeusen JB, Frankel SR, Stock W, Caligiuri MA (2000) Potential mechanisms of human natural killer cell expansion in vivo during low-dose IL-2 therapy. $J$ Clin Invest 106: 117 - 124

Goff BA, Kato D, Schmidt RA, Ek M, Ferry JA, Muntz HG, Cain JM, Tamimi HK, Figge DC, Greer BE (1994) Uterine papillary serous carcinoma: pattern of metastatic spread. Gynecol Oncol 54: 264-268

Grushko TA, Filiaci VL, Mundt AJ, Ridderstrale K, Olopade OI, Fleming GF (2008) Gynecologic Oncology Group. An exploratory analysis of HER-2 amplification and overexpression in advanced endometrial carcinoma: a Gynecologic Oncology Group study. Gynecol Oncol 108: 3-9

Hendrickson M, Ross J, Eifel P, Martinez A, Kempson R (1982) Uterine papillary serous carcinoma: a highly malignant form of endometrial adenocarcinoma. Am J Surg Pathol 6: 93-108

Hu Z, Sun Y, Garen A (1999) Targeting tumor vasculature endothelial cells and tumor cells for immunotherapy of human melanoma in a mouse xenograft model. Proc Natl Acad Sci USA 96: 8161-8166

$\mathrm{Hu} \mathrm{Z}$, Garen A (2000) Intratumoral injection of adenoviral vectors encoding tumor-targeted immunoconjugates for cancer immunotherapy. Proc Natl Acad Sci USA 97: 9221-9225

Hu Z, Garen A (2001) Targeting tissue factor on tumor vascular endothelial cells and tumor cells for immunotherapy in mouse models of prostatic cancer. Proc Natl Acad Sci USA 98: 12180-12185

Jemal A, Siegel R, Ward E, Hao Y, Xu J, Thun MJ (2009) Cancer statistics, 2009. CA Cancer J Clin 59: 225-249

Jewell E, Secord AA, Brotherton T, Berchuck A (2006) Use of trastuzumab in the treatment of metastatic endometrial cancer. Int J Gynecol Cancer 16: $1370-1373$

Kato S, Espinoza N, Lange S, Villalon M, Cuello M, Owen GI (2008) Characterization and phenotypic variation with passage number of cultured human endometrial adenocarcinoma cells. Tissue Cell 40: 95-102

Kato S, Pinto M, Carvajal A, Espinoza N, Monso C, Bravo L, Villalon M, Cuello M, Quest AF, Suenaga A, Brosens JJ, Owen GI (2005) Tissue factor is regulated by epidermal growth factor in normal and malignant human endometrial epithelial cells. Thromb Haemost 94: 444-453

Kaushal V, Mukunyadzi P, Siegel ER, Dennis RA, Johnson DE, Kohli M (2008) Expression of tissue factor in prostate cancer correlates with malignant phenotype. Appl Immunohistochem Mol Morphol 16: 1-6

Krikun G, Hu Z, Osteen K, Bruner-Tran KL, Schatz F, Taylor HS, Toti P, Arcuri F, Konigsberg W, Garen A, Booth CJ, Lockwood CJ (2010) The immunoconjugate 'icon' targets aberrantly expressed endothelial tissue factor causing regression of endometriosis. Am J Pathol 176: $1050-1056$

Levenback C, Burke TW, Silva E, Morris M, Gershenson DM, Kavanagh JJ, Wharton JT (1992) Uterine papillary serous carcinoma (USPC) treated with cisplatin, doxorubicin, and cyclophosphamide (PAC). Gynecol Oncol 46: 317-321

Mueller BM, Reisfeld RA, Edgington TS, Ruf W (1992) Expression of tissue factor by melanoma cells promotes efficient hematogenous metastasis. Proc Natl Acad Sci USA 89: 11832 - 11836

Ortaldo JR, Woodhouse CS, Morgan Jr AC, Herberman RB, Cheresh DA, Reisfeld RA (1987) Analysis of effector cells in human antibodydependent cellular cytotoxicity with murine monoclonal antibodies. J Immunol 138: $3566-3572$

Papetti M, Herman IM (2002) Mechanisms of normal and tumor-derived angiogenesis. Am J Physiol Cell Physiol 282: C947-C970

Presta L, Sims P, Meng YG, Moran P, Bullens S, Bunting S, Schoenfeld J, Lowe D, Lai J, Rancatore P, Iverson M, Lim A, Chisholm V, Kelley RF, Riederer M, Kirchhofer D (2001) Generation of a humanized, high affinity anti-tissue factor antibody for use as a novel antithrombotic therapeutic. Thromb Haemost 85: 379-389

Ruf W (2007) Tissue factor and PAR signaling in tumor progression. Thromb Res 120(suppl 2): S7-S12

Santin AD, Bellone S, Gokden M, Cannon MJ, Parham GP (2002) Overexpression of HER-2/Neu in uterine serous papillary cancer. Clin Cancer Res 8: $1271-1279$

Santin AD, Bellone S, Roman JJ, McKenney JK, Pecorelli S (2008) Trastuzumab treatment in patients with advanced or recurrent endometrial carcinoma overexpressing HER2/neu. Int J Gynecol Obstet 102: 128-131

Santin AD, Bellone S, Van Stedum S, Bushen W, De Las Casas LE, Korourian S, Tian E, Roman JJ, Burnett A, Pecorelli S (2005b) Determination of HER2/Neu status in uterine serous papillary carcinoma: comparative analysis of immunohistochemistry and fluorescence in situ hybridization. Gynecol Oncol 98: 24-30

Santin AD, Bellone S, Van Stedum S, Bushen W, Palmieri M, Siegel ER, De Las Casas LE, Roman JJ, Burnett A, Pecorelli S (2005a) Amplification of c-erbB-2 oncogene. A major prognostic indicator in uterine serous papillary carcinoma. Cancer 104: $1391-1397$

Santin AD, Hermonat PL, Ravaggi A, Chiriva-Internati M, Zhan D, Pecorelli S, Parham GP, Cannon MJ (1999) Induction of human papillomavirusspecific CD4+ and CD8+ lymphocytes by E7 pulsed autologous dendritic cells in patients with HPV16 and 18 positive cervical cancer. J Virol 73: $5402-5410$

Santin AD, Siegel ER, Bellone S, Palmieri M, Thomas M, Cannon MJ, Kay HH, Roman JJ, Burnett A, Pecorelli S (2005c) Racial differences in overexpression of epidermal growth factor type II receptor (HER2/Neu): a major prognostic indicator in uterine serous papillary cancer. Am J Obstet Gyneco 192: 813-818

Schwartz PE (2006) The management of serous papillary uterine cancer. Curr Opin Oncol 18: 494-499

Tezel TH, Bodek E, Sonmez K, Kaliappan S, Kaplan HJ, Hu Z, Garen A (2007) Targeting tissue factor for immunotherapy of choroidal neovascularization by intravitreal delivery of factor VII-Fc chimeric antibody. Ocul immunol inflamm 15: 3-10

Villella JA, Cohen S, Smith DH, Hibshoosh H, Hershman D (2006) HER-2/Neu overexpression in uterine papillary serous cancers and its possible therapeutic implications. Int J Gynecol Cancer 16: 1897-1902

Waxman E, Ross JB, Laue TM, Guha A, Thiruvikraman SV, Lin TC, Konigsberg WH, Nemerson Y (1992) Tissue factor and its extracellular soluble domain: the relationship between intermolecular association with factor VIIa and enzymatic activity of the complex. Biochemistry 31: $3998-4003$

Yu JL, May L, Lhotak V, Shahrzad S, Shirasawa S, Weitz JI, Coomber BL, Mackman N, Rak JW (2005) Oncogenic events regulate tissue factor expression in colorectal cancer cells: implications for tumor progression and angiogenesis. Blood 105: 1734-1741 